\title{
Case report on multiple pathologies in an adolescent sickle cell disease patient in Ghana
}

\begin{abstract}
Sickle cell Disease is the most common genetic disorder in children living in subSaharan Africa with a disease burden estimated between $2-4 \%$ in malaria endemic regions. The pathologies commonly affect multiple organs and present with other comorbidities that complicate the disease process, resulting in diagnostic and management challenges. This case study presents a scenario of a sickle cell patient with multiple long term complications and Deep Vein Thrombosis (DVT) as a co-morbid condition. He did not benefit from early diagnosis and preventive management therapies. This 12-year-old known SCD patient presented with 2 months history of inability to walk, weight loss and pain in both legs to a tertiary hospital in Ghana. On examination he was wasted (Weight for Height $\mathrm{z}$-score <-3SD) and pale. He had palpable axillary and inguinal lymph nodes. His right leg was swollen, warm, erythematous and tender. $\mathrm{He}$ had a gibbus deformity of the lower thoracic spine. Investigations revealed Hemoglobin $7.1 \mathrm{~g} / \mathrm{dl}$, WBC of $13.51 \mathrm{X} 109 / \mathrm{dl}$ with Neutrophils (65.3\%). ESR-117, INR-1.05, Prothrombin Time-14.3secs and blood sugar-6.5mmol/L. Radiological findings revealed features suggestive of sickle cell disease with Thoracolumbar spondylodiscitis, likely pyogenic. Bilateral Avascular Necrosis of the femoral head, Septic arthritis of the right hip and left shoulder joint, Osteomyelitis of the left 8 th and 9th ribs. Doppler Ultrasound of the lower limb revealed Right Popliteal and Posterior Tibial Vein Thrombosis with Pyomyositis. The patient was treated with Enoxaparin, Warfarin and IV antibiotics (Clindamycin and Ciprofloxacin). Follow ups with a repeat Doppler finding revealed a completely resolved thrombus with no evidence of DVT and normal INR and PT. Attention therefore needs to be paid to a multidisciplinary preparedness and response approach to the management of SCD patients, as presented in this case report, to improve the quality of life, mitigate disability and reduce mortality.
\end{abstract}

\author{
Volume 2 Issue 2 - 2016
}

\begin{abstract}
Ashong J,' Ansong D, ,.2 Dogbe J,, ${ }^{1,2}$ Osei Akoto A, ,', Amankwa AT,' Paintsil V,' OseiTutu L,' Sylverken J,' Hammond C'

'Komfo Anokye Teaching Hospital, Ghana

${ }^{2}$ Kwame Nkrumah University of Science and Technology, Ghana

Correspondence: Joslin Dogbe, Department of Child Health, Kwame Nkrumah University of Science and Technology and the Komfo Anokye Teaching Hospital, P.O. Box 1934, Kumasi-Ghana, Tel+23324427I70l,Email slimdogbe@gmail.com
\end{abstract}

Received: January 15, 2016 | Published: April 13, 2016

\section{Introduction}

Sickle cell Disease is the most common genetic disorder in children living in sub-Saharan Africa. ${ }^{1}$ The burden of disease is estimated to range between $2-4 \%$ in malaria endemic regions. ${ }^{2}$ The disease is known to cause more acute episodes in patient presenting with SS, SC and S-beta-thal and also now known to cause multiple organ pathologies and long term morbidities and eventual mortality. ${ }^{3}$ The pathologies commonly affect the brain (stroke), eyes (retinopathy), kidney (micro and macro albuminuria), Bones (acute pain, aseptic necrosis, osteomyelitis and skeletal deformities) heart (cardiomyopathy and pulmonary hypertension), lungs (Acute Chest Syndrome) and overwhelming bacterial infections. ${ }^{3-9}$ Early detection and appropriate follow up with prompt therapy and preventive measure like folic, penicillin $\mathrm{V}$ prophylaxis and immunization against encapsulated organisms like streptococcus pneumonia and Haemophilus Influenzae bacterial are known to improve survival and quality of health. ${ }^{10}$ SCD presents with other comorbidities that complicates the disease and presents with diagnostic and management challenges. This case study presents a scenario of a sickle cell patient with long term complications and Deep Vein Thrombosis (DVT) as a co-morbid condition, who did not benefit from early diagnosis and preventive management therapies.

\section{Case report}

A 12-year-old boy was diagnosed with Sickle Cell Disease (SCD) with genotype SS about one year prior to. He presented with 2 months history of inability to walk and pain in both legs to Komfo Anokye Teaching Hospital in Kumasi, Ghana. The complaints were associated with marked weight loss and generalized body pain. He had been admitted about 2 weeks prior to the onset of current symptoms on account of abdominal pain and anaemia where he was haemo-transfused, given medications and subsequently discharged. There were no other significant findings in the past medical history, immunization history, nutritional and developmental histories. On examination he was found to be wasted (Weight for Height z-score<3SD), pale, afebrile and anicteric. He had palpable axillary and inguinal lymph nodes (each measuring about $1 \mathrm{~cm}$ to $1.5 \mathrm{~cm}$, mobile, non-tender and not matted). Vital signs were normal on admission. Other significant examination findings were obvious swelling of the right leg which was warm to touch, erythematous and tender on palpation. He had a gibbus deformity of the lower thoracic spine with no remarkable neurological findings in the lower limbs. A diagnosis of SCD with vaso-occlusive crises and cellulitis of the right leg was made with differential diagnosis of osteomyelitis, Deep Vein Thrombosis and Potts disease. Initial investigations revealed WBC of $13.51 \mathrm{X} 10^{9} /$ dl with Neutrophils 8.83(65.3\%) Lymphocytes 4.27(31.6\%) and Monocytes 0.25(1.9\%), Hemoglobin 7.1g/dl, MCV-70.7, MCH-22.4, Platelets: 538, ESR-117, INR-1.05, Prothrombin Time-14.3secs and blood sugar- $6.5 \mathrm{mmol} / \mathrm{L}$. Malaria parasites were not seen on the blood smear and patient was negative for Retro-Viral Screen for HIV. Other investigations included Doppler Ultrasound, Chest X-ray, Pelvic X-ray, Thoraco-lumbo-sacral spine X-ray (Figure 1, Figure 2, Figure 3 , Figure 4, Figure 5, Figure 6, Figure 7, Figure 8, Figure $9 \&$ Figure 
10). Blood culture and sensitivity could not be done at the time of admission as microbiology service in the hospital had a brief logistic challenge. Radiological findings revealed the following: Reduction in the vertebral body heights of T7-T10 with associated reduction in the intervertebral disc spaces and crowding of the posterior ribs. A paravertebral soft tissue mass extending from T4 vertebral level to T11. Coarse trabeculation and sclerosis of the ribs noted. Expansion of the anterior end of the left $8^{\text {th }}$ rib with ill-defined lytic areas. Buckling of the cortex of the lateral aspect of the left $9^{\text {th }}$ rib, suggestive of a fracture. The imaged portion of the proximal humerus shows periarticular osteopenia. Also noted was relatively small left humeral head with left glenohumeral joint space. There are patchy homogenous opacities in both lung fields predominantly in the lower zones. There was associated silhouetting of the hemi diaphragms bilaterally and the cardiac shadow. There was generalized sclerosis of the imaged pelvic bones with coarsening of the trabeculae. The right femoral head was deformed and expanded with sclerosis and lytic areas within. There was associated narrowing of the right hip joint space. The left femoral head also showed patchy lucencies. No deformity of the left femoral head seen. The left hip joint space appeared normal. Also noted was fusion of the sacroiliac joints bilaterally. There was diffuse sclerosis of the imaged vertebrae with coarse trabeculae. The vertebral endplates of L1/L2 and L3/L4 showed sharp depression at the margins with a flat base centrally giving it the $\mathrm{H}$ shaped appearance. Also noted were ill-defined lytic areas in the L3 to L5 vertebrae with associated end plate irregularities and reduced intervertebral disc spaces at L3/L4 and L4/L5. No paravertebral soft tissue mass seen. No fracture or listhesis seen. Changes of the thoracic spine were described under the chest x-ray.

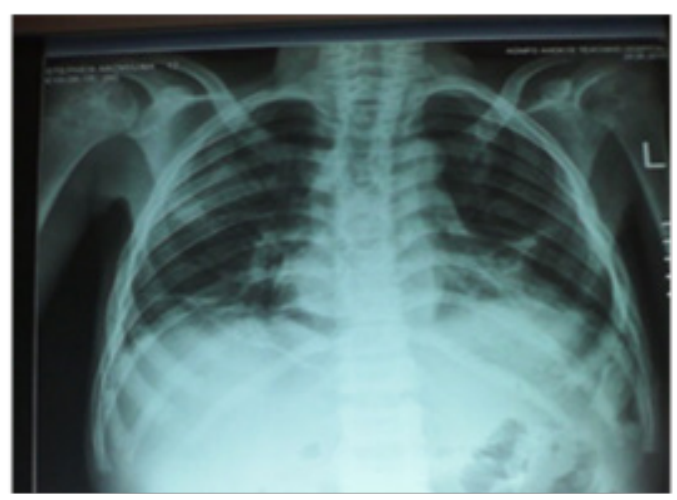

Figure I Chest X-ray of patient.

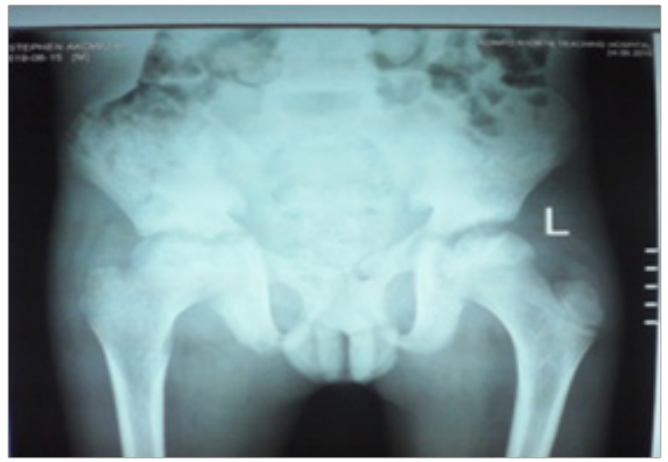

Figure 2 Pelvic $X$-ray of patient.

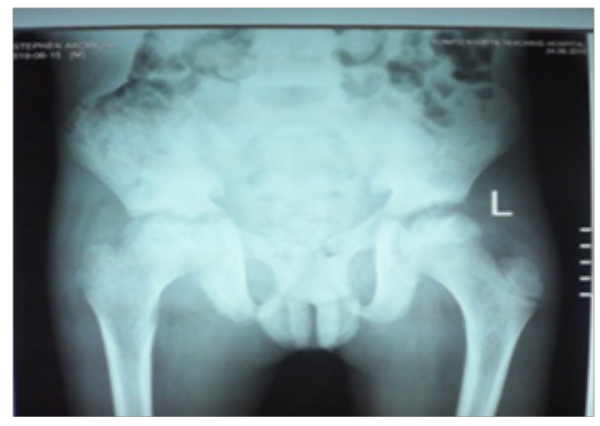

Figure 3 Pelvic X-ray of patient.

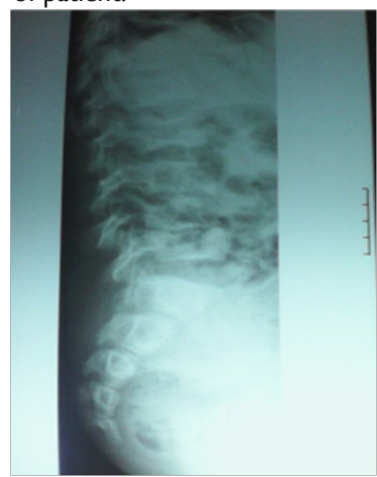

Figure 4 Lateral lumbo sacral spine.

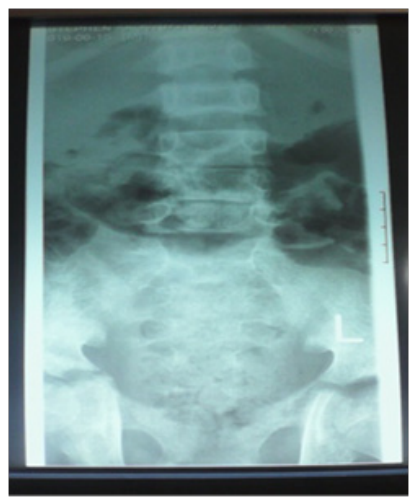

Figure 5 AP view lumbo sacral spine.

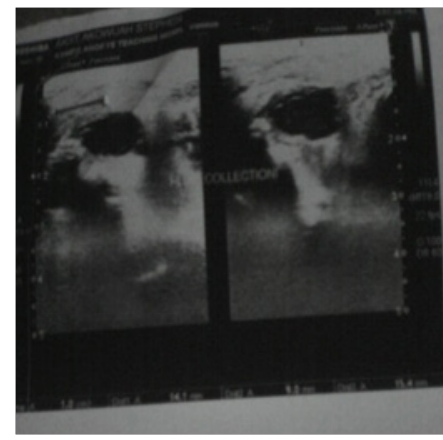

Figure 6 Doppler ultrasound of patient. 


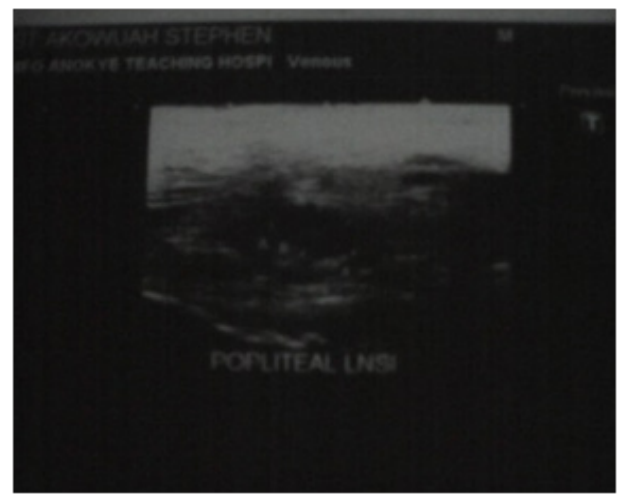

Figure 7 Doppler ultrasound of patient.

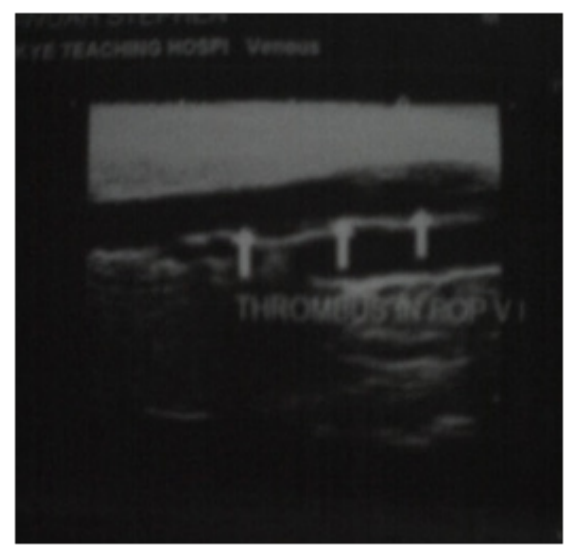

Figure 8 Doppler ultrasound of patient.

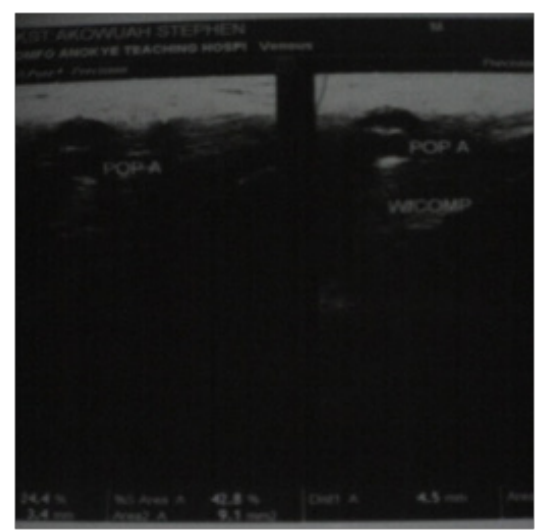

Figure 9 Doppler ultrasound of patient.

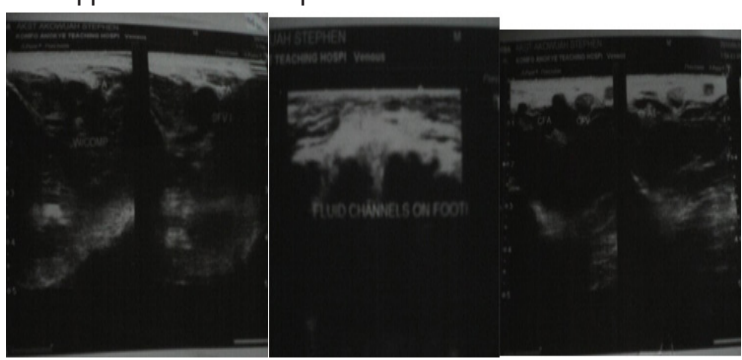

Figure 10 Doppler ultrasound of patient.
These radiological diagnostic features were suggestive of sickle cell disease with Thoracolumbar spondylodiscitis, likely pyogenic; Bilateral Avascular Necrosis of the femoral head (early on the left); Septic arthritis of the right hip and left shoulder joint; Osteomyelitis of the left $8^{\text {th }}$ and $9^{\text {th }}$ ribs. Doppler Ultrasound of the lower limb revealed the following: The right common femoral and superficial femoral veins were of normal lumen with good wall to wall compressibility, good colour doppler and spectral wave form properties. The right popliteal and posterior tibial veins however showed extensive echogenic intraluminal-filling defect with resultant loss of wall-towall compressibility (percentage stenosis $76 \%$ ). The accompanying arteries were of normal size and caliber and showed good colour doppler and spectral properties. There was thickening of the subcutaneous tissue with dilated fluid channels seen in the right foot. Inguinal as well as popliteal lymph nodes with retention of their fatty hilum noted averaging $0.9 * 0.5 \mathrm{~cm}$. Also noted was a $1.4 * 0.9 * 1.5 \mathrm{~cm}$ (volume about $1.0 \mathrm{ml}$ ) anechoic collection with low-level internal echoes at the medial aspect of the proximal thigh muscles; suggestive of inflammatory changes. Based on the Doppler findings a clinical diagnosis of Right Popliteal and Posterior Tibial Vein Thrombosis with Pyomyositis in a Sickle Cell Disease patient was considered and patient was subsequently administered subcutaneous Enoxaparin $40 \mathrm{mg}$ daily as well as Warfarin $3 \mathrm{mg}$ nocte, IV Clindamycin $150 \mathrm{mg}$ qid, IV Ciprofloxacin. After 2days of Warfarin and Enoxaparin, INR and PT were repeated and results were 1.1 and $15.1 \mathrm{~s}$ respectively. The child was followed up closely for four weeks and subsequently discharge. A repeat Doppler finding revealed a completely resolved thrombus with no evidence of DVT.

\section{Discussion}

Sickle cell disease a genetic disorder of the red cell but frequently associated with multiple end organ complications if not diagnosed at birth and managed appropriately. ${ }^{11,12}$ The patient presented in this case report showed up with variety of complications that can occur in SCD patients if adequate effort is not placed on early diagnosis and prevention of complication. ${ }^{11,13}$ The history suggest that patient was not offered early diagnosis and initiation of preventive measure like the administration of Folic acid and Penicillin V. The occurrence of multiple pathologies related to SCD is therefore not unexpected. The level of wasting and malnutrition could not be attributed to the SCD alone since the existence of chronic diseases like tuberculosis or recurrently acute episodic infections in Sickle Cell Disease could contribute to the level of muscle wasting and malnutrition. Studies have shown that SCD patients are more likely to become malnourished compared to their age and sex match. ${ }^{14,15}$ The lack of early diagnosis and management of the disease and the morbidities acquired are sufficient to cause wasting and malnutrition. It is well established that SCD patients are at risk of infections more than the general population. ${ }^{16-18}$ The risk is estimated to be about 36 times for encapsulated infections. ${ }^{17}$ Streptococcus pneumonia, Haemophilus Influenzae Type $b(\mathrm{Hib})$ and Salmonella Typhi and Para Typhi are the most common organisms responsible for infection in SCD patient. ${ }^{17,19-21}$ The occurrence of multiple bone and joint infections make Salmonella species the most likely organism to be responsible for the septic arthritis of the joints and osteomyelitis. Another potential organism to cause such a disseminated infection in the patient is staphylococcus aureus which together with Salmonella species are said to be the two most common causes of osteomyelitis in children with sickle cell anemia. ${ }^{22}$ The occurrence of gibbus in a malnourished child as present in this case, allows clinicians to consider tuberculosis 
as potential diagnosis worth investigating and managing. The child had a BCG scar, indicative of immunization but this does not sufficiently rule out tuberculosis of the vertebra. The risk of multiple infections was high since the child was not on routine Penicillin V and had no protection from $\mathrm{Hib}$ and Streptococcus pneumoniae vaccines. He was therefore at risk of overwhelming encapsulated infections. ${ }^{23,24}$ The lack of blood culture results was a major limitation in addressing the role bacterial infection contributed to the development of the pathologies. Nevertheless patient responded to a course of antibiotics and other treatments provided.

Aseptic necrosis of the large bone heads is a common manifestation in the older SCD patients. ${ }^{25,26}$ The progression of aseptic necrosis is facilitated by malnutrition and secondary bacterial infections. This child presented with significant level of malnutrition (Weight for Height z-score <-3SD), osteopenia and evidence of joint space narrowing are clearly risk factors for progressive aseptic necrosis. Similar explanation above could account for the pathological rib fractures and the gibbus observed in this child. Acute Chest Syndrome (ACS) is one of the life threatening conditions of SCD and is usually confused with pneumonia in children. ${ }^{27,28}$ Clinicians should have high index of suspicion for ACS. This child did not present with ACS but radiological evidence of opacities in the lung field demonstrates past occurrence of ACS. DVT is not uncommon disease in children and cases have been reported..$^{29,30}$ The occurrence of this disease is associated with risk factors such as cancers, trauma, infections, venous catheterization, sickle cell disease and coagulation disorders. ${ }^{29}$ This patient had two risk factors for DVT; Sickle Cell Disease and possible multiple infections. ${ }^{31}$ In addition to these risk factors, was the fact that this child was immobile for most of the time during the onset of the illness (suffering from septic arthritis of the hip and pyomyositis). In SCD patients, presentation with lower limb pain and tenderness is mostly associated with vaso-occlusive episodes and/or osteomyelitis in areas with high prevalence of the disease. Clinicians should have a high index of suspicion for DVT since it can occur in cases with multiple risk factors. This is critical since the occurrence of Pulmonary Embolism (PE) from the DVT will be life threatening and could also be easily confused to be ACS in a SCD patient and patient would be mismanaged. This short case report therefore tried to highlight some of the uncommon pathologies amongst others that might arise in a SCD patient and to alert clinicians to look out for DVT as an uncommon differential diagnosis in swollen limbs in these patients. It is worth noting that attention needs to be paid to a multidisciplinary preparedness and response approach to the management of SCD patients, as presented in this case report, to mitigate or minimize disability and mortality.

\section{Acknowledgements}

None.

\section{Conflict of interest}

The author declares no conflict of interest.

\section{References}

1. Gladwin MT, Rees DC, Williams TN. Sickle-cell disease. Lancet. 2010;376(9757):2018-2023.
2. Piel FB, Patil AP, Howes RE, et al, Global epidemiology of Sickle haemoglobin in neonates: a contemporary geostatistical model-based map and population estimates. Lancet. 2013;381(9861):142-151.

3. Adams RJ, Hess DC, Nichols FT, et al. Pathophysiology and treatment of stroke in sickle-cell disease: present and future. Lancet Neurol. 2006;5(6):501-512.

4. Condon PI, GR Serjeant. "Ocular findings in homozygous sickle cell anemia in Jamaica." Br J Ophthalmol. 1972;60(5):361-364.

5. McKie KT, Hanevold CD, Hernandez C, et al. Prevalence, prevention, and treatment of microalbuminuria and proteinuria in children with sickle cell disease. J Pediatr Hematol Oncol. 2007;29(3):140-144.

6. Aguilar C, Neumayr L, Vichinsky E. Bone and joint disease in sickle cell disease. Hematology/oncology clinics of North America. 2005;19(5):929941.

7. Gladwin MT, Sachdev V. Cardiovascular abnormalities in sickle cell disease. J Am Coll Cardiol. 2012;59(13):1123-1133.

8. Aggarwal A, Castro OL, Oneal PA, et al. Acute chest syndrome: sickle cell disease. European Journal of Hematology. 2011;87(3):191-207.

9. Booth C, Inusa B, Obaro SK. Infection in sickle cell disease: A review. Int J Infect Dis. 2010;14(1):e2-12.

10. Benjamin S, Charles HP, Chris AVB, et al. Invasive pneumococcal infections in children with sickle cell disease in the era of penicillin prophylaxis, antibiotic resistance, and 23-valent pneumococcal polysaccharide vaccination. J Pediatr. 2003;143(4):438-444.

11. Cober MP, Phelps SJ. Penicillin prophylaxis in children with sickle cell disease. J Pediatr Pharmacol Ther. 2010;15(3):152-159.

12. Amato A, Giordano PC. Screening and genetic diagnosis of Hemoglobinopathies in Southern and Northern Europe: Two examples. Mediterr J Hematol Infect Dis. 2009;1(1):e2009007.

13. Ansong D, Akoto AO, Ocloo D, et al. Sickle cell disease: management options and challenges in developing countries. Mediterr J Hematol Infect Dis. 2013;5(1):e2013062.

14. Finan AC, Elmer MA, Sasanow SR, et al. Nutritional factors and growth in children with sickle cell disease. Am J Dis Child. 1998;142(2):237-240.

15. Reed JD, Redding-Lallinger R, Orringer EP. Nutrition and sickle cell disease. Am J Hematol. 1987;24(4):441-455.

16. Hirst C, Owusu OS. Prophylactic antibiotics for preventing pneumococcal infection in children with sickle cell disease. Cochrane Database Syst Rev. 2012;9:CD003427.

17. Ramakrishnan M, Moïsi JC, Klugman KP, et al. Increased risk of invasive bacterial infections in African people with sickle-cell disease: a systematic review and meta-analysis. Lancet Infect Dis. 2010;10(5):329-337.

18. Williams TN, Uyoga S, Macharia A, et al. Bacteraemia in Kenyan children with sickle-cell anaemia: a retrospective cohort and case-control study. Lancet. 2009;374(9698):1364-1370.

19. Hook EW, Campbell CG, Weens Hs, et al. Salmonella osteomyelitis in patients with sickle-cell anemia. $N$ Engl J Med. 1957;257(9):403-407.

20. Landesman SH, Rao SP, Ahonkhai VI. Infections in children with sickle cell anemia Special reference to pneumococcal and salmonella infections. J Pediatr Hematol Oncol. 1982;4(4):407-416.

21. Elbashier AM, Al-Salem AH, Aljama A. Salmonella as a causative organism of various infections in patients with sickle cell disease. Ann Saudi Med. 2003;23(6):358-362. 
22. Lampe RM. Osteomyelitis. In: Kliegman RM, et al. editors. Nelson Textbook of Pediatrics. 18th ed. WB Saunders, Philadelphia, USA: PA 2007. p. 2841-2845.

23. Overturf GD. American academy of pediatrics. Committee on infectious diseases. Technical report: prevention of pneumococcal infections, including the use of pneumococcal conjugate and polysaccharide vaccines and antibiotic prophylaxis. Pediatrics. 2000;106(2 Pt 1):367-376.

24. Obaro SK, Madhi SA. Bacterial pneumonia vaccines and childhood pneumonia: are we winning, refining, or redefining? Lancet Infect Dis 2006;6(3):150-161.

25. Milner PF, Kraus AP, Sebes JI, et al. Sickle cell disease as a cause of osteonecrosis of the femoral head. N Engl J Med. 1991;325(21):14761481 .

26. http://adc.bmj.com/content/55/3/175.full.pdf
27. Vichinsky EP, Styles LA, Colangelo LH, et al. Acute chest syndrome in sickle cell disease: clinical presentation and course. Blood. 1997;89(5):1787-1792.

28. Vichinsky EP, Neumayr LD, Earles AN, et al. Causes and outcomes of the acute chest syndrome in sickle cell disease. $N$ Engl J Med. 2000;342(25):1855-1865.

29. Van Ommen CH, Heijboer H, Büller HR, et al. Venous thromboembolism in childhood: A prospective two-year registry in The Netherlands. $J$ Pediatr. 2001;139(5):676-681.

30. Stein PD, Beemath A, Meyers FA, et al. Deep venous thrombosis and pulmonary embolism in hospitalized patients with sickle cell disease. $\mathrm{Am}$ J Med. 2006;119(10):897.

31. http://www.mjhid.org/article/download/7909/e2011024 